\title{
Propaganda de inseticidas: estratégias para minimização e ocultamento dos riscos no ambiente doméstico
}

\section{Insecticides advertisements: strategies for minimization and concealment of household risks}

\author{
Jane Silva Maia Castro \\ Secretaria Estadual de Saúde do Rio de Janeiro. Subsecretaria de \\ Vigilância em Saúde. Rio de Janeiro, RJ, Brasil. \\ E-mail: janemaiaळglobo.com

\section{Brani Rozemberg} \\ Centro de Estudos Saúde do Trabalhador e Ecologia Humana. \\ Escola Nacional de Saúde Pública. Fundação Oswaldo Cruz. Rio \\ de Janeiro, RJ, Brasil. \\ E-mail: branirozemberg®uol.com.br
}

\section{Resumo}

Este trabalho tem como objetivo fazer uma análise e propor uma discussão sobre as estratégias adotadas pelas propagandas de inseticidas para uso no ambiente doméstico, e suas implicações para a saúde pública. Foram analisadas peças publicitárias de inseticidas veiculadas na mídia televisiva no período de 2008 a 2010. Como critério de seleção das peças, foram escolhidas quatro peças publicitárias de inseticidas que foram ao ar em dois canais de TV aberta, nos horários da manhã e da noite, ao longo do período citado. Para a análise dessas peças, utilizou-se a observação da propaganda na TV. O método utilizado foi a análise de conteúdo. As categorias geradas pela análise foram: apelo ao status do usuário; ocultação e minimização dos riscos; símbolos de modernidade e cientificidade; representações de um mundo asséptico; e representações de força, poder e controle. Concluímos, então, que todas as propagandas analisadas utilizaram estratégias que ocultam os riscos toxicológicos dos inseticidas no ambiente doméstico e não cumprem a legislação brasileira. Palavras-chave: Vigilância Sanitária; Televisão; Análise de Conteúdo; Comunicação e Saúde; Peças Publicitárias.

\section{Correspondência}

Jane Silva Maia Castro

Rua Otávio Carneiro, 13, apto 702, Icaraí.

CEP 24230-190. Niterói, RJ, Brasil. 


\section{Abstract}

The study aims to analyze and propose a discussion on insecticide ads for domestic use and their implications on public health. We analyzed insecticide ads broadcast on the television between the years of 2008 and 2010. As selection criteria four insecticide ads were chosen, which aired on two television channels, in the morning and in the evening, over that period. The ads were analyzed by watching their broadcast on television. The method used was content analysis. The categories generated by the analysis were: appeal to the user's status; concealment and downscaling of risks; symbols of modernity and rationality; representations of an aseptic world; and representations of strength, power and control. We, therefore, conclude that all the evaluated ads adopted strategies that concealed the risks of domestic insecticides and did not comply with Brazilian legislation.

Keywords: Health Communication; Television; Health Surveillance; Content Analysis; Advertising Pieces.

\section{Introdução}

O Brasil apresenta uma complexa situação no que tange ao controle de doenças transmissíveis. As ações implementadas visando a erradicação dos agentes patogênicos, ou dos seus vetores, se dão através de controle químico com a utilização de agrotóxicos, principalmente os inseticidas (Gurgel, 2005; Londres, 2011).

Em todo o mundo, 100 mil agentes químicos sintéticos estão atualmente no mercado. A cada ano, mil novas substâncias são lançadas, a maioria delas sem serem testadas ou avaliadas adequadamente (Colborn; Dumnoski; Myers, 2002).

A legislação brasileira diferencia os produtos de uso na agricultura dos utilizados em ambientes confinados. Os primeiros, segundo a Lei n. 7.802, de 11/07/1989, são classificados como agrotóxicos; os segundos são classificados, pela Lei n. 6.36o, de 23/o9/1976, como saneantes domissanitários, e definidos como: "substância ou preparação destinada à higienização, desinfecção ou desinfestação domiciliar, em ambientes coletivos ou públicos" (Brasil, 1976, 1989).

A lógica empregada nas políticas de controle dos vetores em ambiente doméstico, baseada no uso de inseticidas, é semelhante ao modelo de uso de agrotóxicos para controle fitossanitário na agricultura. No entanto, tem se acumulado críticas bastante consistentes sobre a insustentabilidade do modelo agrícola químico-dependente. Já no ambiente urbano, são poucas as críticas e relativamente escassos os estudos evidenciando as decorrências deste modelo de "proteção à saúde", dedicado ao controle das chamadas "pragas urbanas e domésticas".

Segundo o Anuário da ABIPLA (Associação Brasileira das Indústrias de Produtos de Limpeza e Afins), o mercado de inseticidas faturou, em 2010, cerca de R\$ 600 milhões, com mais de 100 mil unidades vendidas. A categoria em aerossol teve o crescimento mais expressivo em volume, com 5,1\%. Destaque para os inseticidas elétricos com novas versões automáticas, que liberam o produto periodicamente para a proteção contra pernilongos, mosquitos e moscas. (Abipla, 2011; Neves, 2012).

Segundo dados de pesquisa da Nielsen Brasil, o mercado de inseticidas no país teve um crescimento de $240 \%$ nos últimos cinco anos. Os inseticidas são 
comercializados durante todo o ano, mas as maiores vendas se concentram nos meses mais quentes e úmidos, quando os insetos domésticos aparecem com mais frequência. Os produtos são facilmente encontrados nas grandes redes de supermercado e também nos pequenos varejos e mercearias de bairro (Neves, 2012).

Nos supermercados, encontramos uma variedade de produtos e marcas de inseticidas líquidos, em pó, em pasta e até elétricos, com uma grande de diversidade de princípios ativos, o que acarreta possíveis riscos às pessoas (Câmara, 2000). 0 consumidor é atraído pela mídia, que oferece esses produtos como protetores da saúde e como um sinônimo de limpeza (Lombardi; Minuissi; Midio, 1983; Augusto; Carneiro; Martins, 2005).

O surgimento de cepas resistentes aos inseticidas faz com que o consumidor insista no uso, aumentando o risco de intoxicação. A resistência a pesticidas tem sido documentada em mais de 100 espécies de mosquitos e em muitas espécies de outros artrópodes importantes na área da saúde, tais como moscas, piolhos, percevejos, pulgas, baratas e carrapatos (Donalísio; Glasser, 2002; Diel; Facchine; Dall'Agnol, 2003; Oliveira et al., 2005; Braga; Valle, 2007).

Há mais de trinta anos questiona-se, por exemplo, a aspersão ambiental de pesticidas para o controle urbano da dengue por meio da tecnologia que supõe eliminar larvas e o inseto alado. Seu uso prolongado acarreta o desenvolvimento de resistência por parte das espécies e a contínua expansão do número de casos da doença - que se propôs a controlar - em diversas localidades do planeta (Augusto; Carneiro; Martins, 2005).

A precariedade da forma com que, em geral, as substâncias químicas são utilizadas em nosso país, bem como o uso simultâneo de várias delas, geralmente em grandes quantidades, aponta a existência de risco elevado, que pode se tornar, num curto espaço de tempo, um problema de gravíssimas consequências para a saúde pública e para o meio ambiente (Meyer et al., 2003). O consumidor, na maioria das vezes, desconhece as propriedades tóxicas dos componentes dessas formulações (princípio ativo, solvente, propelentes e sinergistas). A falta de preocupação e o desconhecimento da toxidade dos produtos utilizados, por parte de diferentes segmentos sociais, foi uma constatação geral em estudos de Câmara (2000), Lombardi et al. (1983), Diel, Facchine e Dall'Agnol (2003) e Londres (2011).

\section{Os inseticidas domésticos}

O principal grupo químico utilizado como inseticida no ambiente doméstico é o piretroide sintético, amplamente utilizado também para o controle de agentes patogênicos, tanto na produção agrícola como na proteção da saúde humana. Porém, apesar de suas inúmeras vantagens em relação aos demais, pode causar intoxicações em indivíduos expostos às suas diversas apresentações (espirais, sprays ou vaporizadores) (Paiva; Menezes, 2003).

Os inseticidas piretroides são absorvidos pela pele, por inalação e pelo trato gastrintestinal. Com relação à sua ação tóxica, determinam experimentalmente, em ratos, efeitos neurológicos, provavelmente de origem periférica, provocando um quadro de agressividade nos animais, com tremores e um estágio final de intoxicação consistindo de espasmos convulsivos, falta de coordenação e prostração. Estas intoxicações podem ocorrer com exposição a curto, médio ou longo prazo, podem ser crônicas ou agudas e de caráter acidental ou intencional, sendo que a velocidade e quantidade de absorção nas diferentes vias serão determinadas pelas propriedades físico-químicas do agente tóxico, da formulação empregada e por fatores fisiológicos e anatômicos do organismo atingido (Paiva; Menezes, 2003; Larini, 1993).

A notificação dos casos de intoxicação por agrotóxicos (em que se incluem os domissanitários) é habitualmente realizada de modo precário, gerando subnotificação. As causas da subnotificação podem ser muitas e já foram amplamente discutidas na literatura (Moreira et al., 2002; Faria; Fassa; Facchini, 2007; Presgrave; Camacho; Villas Boas, 2009). Entre elas, está o fato de a contaminação por substâncias químicas, muitas vezes, não ser percebida pela população (Augusto, 2003). Por não serem graves, muitas vezes, as intoxicações não exigem internação do indivíduo, ou sequer geram a procura de atendimento médico (Castro, 1999). A população, de uma forma geral, desconhece o nexo entre os sintomas e os agentes químicos (Augusto, 2003). 


\section{Peças publicitárias de inseticidas}

É amplamente conhecido que a comunicação é força poderosa, e que a mídia pode criar, em torno de questões centrais da vida pública, as representações que mais interessam a determinados grupos que detêm o monopólio de sua operacionalização (Rodrigues, 2006; Nascimento, 2007; Dal Col, 2009; Brasil, 2009). ${ }^{1}$

A televisão, o rádio, o jornal, as revistas, e até a indicação de alguém, podem estimular uma determinada ação de consumo, sobretudo porque os lançamentos de marcas e produtos no mercado geralmente são divulgados por um desses meios.

A mídia mais influente continua sendo a televisão. Os elementos que compõem um comercial de TV conduzem o público por uma narrativa sonora e visual que provoca reações de identificação com o universo do produto ou serviço que é divulgado e apresentado (Rodrigues, 2006).

A regulação publicitária no Brasil é executada no âmbito público pelo CDC (Código de Defesa do Consumidor) e pela ANVISA (Agência Nacional de Vigilância Sanitária), e no âmbito privado pelo CONAR (Conselho Nacional de Autorregulamentação Publicitária), sendo os dois primeiros de caráter legislativo e o último de caráter autorregulatório (Rodrigues, 2006).

Tais instâncias analisam as peças publicitárias segundo suas diferentes atribuições, sendo que a Anvisa verifica sua adequação à legislação brasileira e aos regulamentos por ela criados para orientar os anunciantes quanto à prática da publicidade dos produtos sujeitos à sua área de atuação, a vigilância sanitária. Isso inclui também a informação disponibilizada ao consumidor nos rótulos dos produtos. A Anvisa conta com uma gerência específica, a Gerência de Monitoramento e Fiscalização de Propaganda, Publicidade, Promoção e Informação de Produtos Sujeitos à Vigilância Sanitária (Anvisa, 2003).

Apesar da existência de tais instâncias regulatórias, a maioria das pesquisas realizadas sobre propaganda de produtos relacionados à saúde - como alimentos, medicamentos e inseticidas - aponta irregularidades e extrapolação dos limites éticos. A propaganda, muitas vezes, ultrapassa tais limites, desrespeitando os direitos do consumidor e fazendo com que sejam necessários estudos sobre as estratégias por ela utilizadas, de modo a subsidiar a atuação dos setores que respondem por seu controle (Nascimento, 2005; Crivelaro et al., 2006; Resener; Schenkel; Simões, 2006; Nascimento, 2007; Lopes; Almeida Júnior, 2008; Pinto, 2008; Soares, 2008; Rabello; Camargo Júnior, 2012)².

Considerando que o discurso publicitário é uma forma de comunicação específica e dirigida, que alcança sua eficácia persuasiva graças ao uso de inúmeros recursos da linguagem (Rodrigues, 2006), torna-se fundamental identificá-los. 0 presente estudo analisa as estratégias de persuasão de peças publicitárias de inseticidas e faz parte de um estudo mais amplo sobre a percepção pública e a eficácia destas propagandas junto aos consumidores.

\section{Abordagem metodológica}

A seguir analisaram-se quatro peças publicitárias de inseticidas veiculadas na mídia televisiva no período de 2008 a 2010. Como critério de seleção das peças, foram escolhidas quatro peças publicitárias de inseticidas que foram ao ar em dois canais de TV aberta, nos horários da manhã e da noite, ao longo do período citado. Para a análise dessas peças, utilizou-se a observação da propaganda na TV, e recorreu-se também aos storyboards dos filmes publicitários, que foram solicitados ao Arquivo da Propaganda ${ }^{3}$, que os disponibilizou aos autores. Storyboards são conjuntos de fotos das principais cenas dos comerciais com o texto transcrito. No caso da presente publicação, não estão inclusas as imagens das cenas, apenas os roteiros descritivos simples, contendo a descrição do áudio e da imagem de cada cena da peça publicitária. Cabe mencionar que essas peças se encontram também disponíveis no youtube, sendo, portanto, de fácil acesso.

\footnotetext{
1 Informação coletada também no site do Instituto Alana. Organização Não Governamental. Disponível em: 〈http://www.alana.org.br〉. Acesso em: 14 set. 2010.

2 Também foi consultado o material: Santos, S. L.; Batalha, M. O. A ética na propaganda de alimentos: uma análise a partir de comerciais da televisão. Apresentação oral no $45^{\circ}$ Congresso da SOBER, Londrina, 2007.

3 Arquivo da Propaganda. Acervo publicitário. Disponível em: <http://www.arquivo.com.br>. Acesso em: 25 maio 2010
} 
Cada peça foi analisada utilizando o método de análise de conteúdo (Minayo, 2004), e os resultados são apresentados e discutidos tendo como foco a identificação das estratégias adotadas para a persuasão do consumidor.

Essa pesquisa foi aprovada pelo Comitê de Ética da Escola Nacional de Saúde Pública (ENSP) e atende às normas do Conselho Nacional de Ética e Pesquisa.

\section{Resultados e discussão}

\section{Peça publicitária - SBP (2009):}

\section{Quadro I - Roteiro descritivo simples: Análise da peça publicitária - SBP, 2009}

\begin{tabular}{|c|c|c|}
\hline CENAS & VÍDEO & ÁUDIO \\
\hline 1 & $\begin{array}{l}\text { Homem está em casa e atende ao celular. Uma criança passa } \\
\text { diante dele. }\end{array}$ & Homem - Alôo? \\
\hline 2 & Mulher está saindo de um prédio e falando ao celular. & $\begin{array}{l}\text { Mulher - Oi, Amor. Me atrasei. Faz um favor para mim? } \\
\text { H-Claro! } \\
\text { M-Liga o forno e passa SBP na casa? }\end{array}$ \\
\hline 3 & Mulher desliga, compra flores e sorri enquanto dirige. & \\
\hline 4 & $\mathrm{Na}$ casa duas crianças brincam e o homem observa. & $\begin{array}{l}\text { Voz feminina - Não tem lugar no mundo como a casa } \\
\text { da gente. }\end{array}$ \\
\hline 5 & $\begin{array}{l}\text { Aparece a mão do homem sacudindo a embalagem de SBP e } \\
\text { mostrando como destravar a tampa. O homem aperta o spray } \\
\text { pelo ambiente, e a casa aparece envolvida por uma bolha. } \\
\text { Abaixo, a frase: "Atenção. Cuidado. Antes de usar, leia com } \\
\text { atenção as instruções do rótulo". }\end{array}$ & Voz feminina - E não tem proteção como a de SBP. \\
\hline 6 & $\begin{array}{l}\text { A mulher chega com as flores e, quando entra na casa, é } \\
\text { sugerida uma barreira invisível. Ela abraça as crianças e coloca } \\
\text { uma das flores num vaso. Abaixo, a frase: "Única linha à base } \\
\text { de água", ao lado da embalagem de SBP. }\end{array}$ & $\begin{array}{l}\text { Voz feminina-SBP é a única linha de inseticidas feita } \\
\text { à base de água. }\end{array}$ \\
\hline 7 & $\begin{array}{l}\text { É feita uma comparação entre SBP e um inseticida qualquer. } \\
\text { Ambos têm uma flor ao lado. Sob o SBP está escrito ÁGUA. } \\
\text { Sob o outro produto está escrito QUEROSENE. A flor do SBP se } \\
\text { mantém viva, enquanto a outra murcha. Diante do SBP aparece } \\
\text { a frase: "Usa água como solvente". }\end{array}$ & Voz feminina - Age sobre os insetos com eficiência... \\
\hline 8 & $\begin{array}{l}\text { A família está reunida e jantando com a frase abaixo: "Não } \\
\text { agride o ambiente da sua casa". }\end{array}$ & Voz feminina - ...sem agredir o ambiente. \\
\hline 9 & $\begin{array}{l}\text { Aparece a casa protegida por uma bolha. Embaixo aparece } \\
\text { a linha SBP com quatro produtos e a frase em caixa alta: } \\
\text { "TERRIVEL CONTRA OS INSETOS. CONTRA OS INSETOS". }\end{array}$ & $\begin{array}{l}\text { Voz feminina - SBP. Terrivel contra os insetos. Contra } \\
\text { os insetos. }\end{array}$ \\
\hline
\end{tabular}

A peça apresenta o uso do inseticida como símbolo de modernidade e praticidade, com o status de item indispensável à vida cotidiana. Isto é realizado por meio da apresentação de soluções imediatas para os problemas da falta de tempo da mulher moderna que, além de trabalhar fora, exerce os papéis de mãe e esposa.

O papel da publicidade é produzir anúncios que provoquem mudanças não só de opinião, mas tam- bém de sentimento nos receptores. Como discutido por Dal Col (2009) e Brasil (2009), a imagem da mulher bem-sucedida, profissional, econômica, apela emocionalmente para o desejo de identificação com tal status. Apela, ainda, para a imagem do companheiro que ajuda nas tarefas domésticas.

A solicitação da esposa ("- Liga o forno e passa SBP na casa?") é problemática ao incluir duas ações que não deveriam ser realizadas simultaneamente: 
o uso do gás do forno e de um produto inflamável, o que está especificado no rótulo deste último.

A peça adota estratégia de minimização dos riscos ao ressaltar que utiliza água como solvente em lugar do querosene, além de aromatizantes, sem considerar que isto possa levar a uma maior exposição do usuário, que acaba pensando que o uso da água como solvente diminui a toxidade do inseticida. Para tal, o produto anuncia-se como a "Única linha à base de água". O uso da palavra "única" confere um sentido de exclusividade do produto, diferenciando-o dos demais, o que leva o consumidor a escolher o produto que lhe parece especial e distinto e, consequentemente, a atribuir a si mesmo tais caraterísticas.

O comercial apresenta crianças, além de flores, e ainda informa que o produto só é "terrível contra os insetos" e que preserva o meio ambiente. Não informa que o produto é potencialmente tóxico, e ainda contraria a recomendação da rotulagem de que o produto esteja fora do alcance das crianças e dos animais domésticos.

A casa aparece envolvida por uma bolha, imagem sutil e diáfana, sinalizando existir uma proteção do ambiente doméstico em relação ao externo, não pulverizado pelo produto. A utilização da bolha persuade os consumidores por meio de uma analogia, com a ideia de que, se não pulverizarem a casa, ela não estará protegida. Isto caracteriza o princípio da exclusão, que, segundo Dal Col (2009) e Brasil (2009), é um artifício amplamente utilizado pela publicidade. Neste caso, explorando o desejo de segurança e proteção.

\section{Peça publicitária - SBP Automático:}

\section{Quadro 2 - Roteiro descritivo simples: Análise da peça publicitária - SBP Automático}

\begin{tabular}{|c|c|c|}
\hline CENAS & VÍDEO & ÁUDIO \\
\hline 1 & $\begin{array}{l}\text { Mãe e filho passeiam no zoológico. Eles param diante do chimpanzé. o macaco } \\
\text { está sentado num tronco, batendo e agitando as mãos sobre a cabeça. }\end{array}$ & $\begin{array}{l}\text { Criança - Mãe! Olha! O macaco tá } \\
\text { espantando mosquito... }\end{array}$ \\
\hline 2 & O macaco aparece pulando sobre a grama. & Criança $-E$, agora, matando barata... \\
\hline 3 & Mãe e filho se abraçam carinhosamente. & $\begin{array}{l}\text { Mãe - Só lá em casa tem proteção dia e } \\
\text { noite, filho. }\end{array}$ \\
\hline 4 & $\begin{array}{l}\text { Aparece a mãe montando o equipamento com o spray SBP, tendo ao fundo a } \\
\text { embalagem e um vaso de plantas. }\end{array}$ & Voz masculina - Chegou SBP automático. \\
\hline 5 & $\begin{array}{l}\text { O equipamento aparece preso a uma parede emitindo uma espécie de onda, } \\
\text { como se fosse o produto sendo lançado no ambiente. }\end{array}$ & $\begin{array}{l}\text { Voz masculina - Um sistema } \\
\text { revolucionário... }\end{array}$ \\
\hline 6 & $\begin{array}{l}\text { A onda abrange todo o ambiente, onde se encontram um ursinho de pelúcia e } \\
\text { um vaso com flores. }\end{array}$ & ....de proteção contra insetos. \\
\hline 7 & $\begin{array}{l}\text { O equipamento aparece com um fundo branco e um relógio. Abaixo, numa } \\
\text { faixa laranja, aparece a frase: "Avaliado por toxicologistas". }\end{array}$ & É proteção contínua... \\
\hline 8 & $\begin{array}{l}\text { O relógio se move, enquanto a cena se afasta, e aparece uma flor ao lado do } \\
\text { produto. Ao lado do relógio aparece a frase: "15 min." Abaixo surge, em letras } \\
\text { menores e sobre o fundo branco, a frase: "Atenção. Cuidado. Antes de usar, } \\
\text { leia com atenção as instruções do rótulo". Os ponteiros do relógio percorrem } \\
\text { mais } 15 \text { min. Aparece a frase sobre uma faixa laranja: "24 horas". }\end{array}$ & ...com microsprays a cada is minutos. \\
\hline 9 & $\begin{array}{l}\text { Uma nova janela aparece, ao lado, com uma pessoa segurando uma } \\
\text { embalagem de spray inseticida sem marca, com a frase sobre uma faixa } \\
\text { cinza: "I spray de } 3 \text { segundos". }\end{array}$ & $\begin{array}{l}\text { SBP automático solta em } 24 \text { horas a } \\
\text { mesma quantidade que um spray comum. }\end{array}$ \\
\hline 10 & $\begin{array}{l}\text { Mãe e filho chegam a casa. o menino é o primeiro a entrar e está comendo } \\
\text { pipoca. A imagem sugere que ele passa por uma barreira invisível. }\end{array}$ & (Música) \\
\hline II & O menino pega o ursinho de pelúcia e fala com ele. & $\begin{array}{l}\text { Criança - Fica tranquilo que aqui não } \\
\text { tem inseto, viu? }\end{array}$ \\
\hline 12 & $\begin{array}{l}\text { Aparece a casa dentro de uma bolha ainda com o dia claro e, enquanto } \\
\text { vai anoitecendo, aparece o produto anunciado com a frase em caixa alta: } \\
\text { "TERRIVEL CONTRA OS INSETOS. CONTRA OS INSETOS". }\end{array}$ & $\begin{array}{l}\text { Voz masculina - Novo SBP automático. } \\
\text { Terrivel contra os insetos. Contra os } \\
\text { insetos. }\end{array}$ \\
\hline
\end{tabular}


Nesta peça, a presença de um macaco espantando mosquitos e baratas mecanicamente sugere que as práticas de controle mecânico de insetos são primitivas. Contrapondo-se a elas, a propaganda apresenta um dispositivo "revolucionário" no qual um spray de três segundos pulveriza o piretroide durante 24 horas no ambiente de forma automática. Trata-se de uma nova forma de liberação do inseticida, na qual o consumidor não terá sequer o trabalho de acionar o spray, enquanto, na realidade, seu uso contínuo no ambiente implica um risco muito maior de desenvolvimento de resistência dos insetos ao produto.

Essa peça que teria como alvo, a princípio, um público consumidor adulto, adota elementos infantis e a própria criança como protagonista. Dentro das estratégias de convencimento da suposta inocuidade do produto, utiliza a imagem da criança comendo, numa associação inadequada entre alimentos e inseticidas, também ferindo claramente o disposto na legislação.

A representação do ambiente pulverizado como saudável é reforçada pela fala da criança com seu urso de pelúcia ("- Fica tranquilo que aqui não tem inseto, viu?').

Novamente, aqui é adotada a representação da bolha de proteção que envolve a casa. A peça deixa implícito que o produto atua somente contra os insetos, o que não poderia ser afirmado. Ela o faz dando ênfase à expressão "contra os insetos".

\section{Peça publicitária - Baygon:}

Quadro 3 - Roteiro descritivo simples: Análise da peça publicitária - Baygon.

\begin{tabular}{|c|c|c|}
\hline CENAS & VÍDEO & ÁUDIO \\
\hline 1 & Duas crianças brincam no chão da casa & (Música) \\
\hline 2 & Aparece uma barata. As crianças gritam. & Criança - Mãe, barata! \\
\hline 3 & As crianças entram em casa e voltam com a mãe, que traz uma vassoura na mão. & Locutor - Os insetos têm mais... \\
\hline 4 & Ela bate na barata com a vassoura, tentando matar o inseto. & ...poder de se reproduzir... \\
\hline 5 & Quanto mais ela bate, mais a barata se reproduz. & ...do que você tem de acabar com eles? \\
\hline 6 & $\begin{array}{l}\text { A mãe aparece segurando uma embalagem do inseticida. Abaixo, a frase: } \\
\text { "ATENÇÃO, CUIDADO! Antes de usar, leia as instruções do rótulo". }\end{array}$ & $\begin{array}{l}\text { Use Baygon Af̧ão Total. } \\
\text { Voz em off canta - o poder é seu! }\end{array}$ \\
\hline 7 & $\begin{array}{l}\text { A embalagem aparece no centro da tela, envolvida por uma luz verde. A frase } \\
\text { anterior permanece no vídeo, com a logomarca do produto ao lado. }\end{array}$ & $\begin{array}{l}\text { Locutor - Sua nova fórmula age em } \\
\text { segundos. Poder contra as baratas... }\end{array}$ \\
\hline 8 & $\begin{array}{l}\text { A imagem aparece dividida em duas: de um lado baratas mortas; do } \\
\text { outro, mosquitos mortos e um círculo vermelho no alto com a indicação de } \\
\text { combate ao mosquito da dengue. Abaixo, a frase: "COMPROVADO POR TESTES } \\
\text { LABORATORIAIS" e a logomarca do produto. }\end{array}$ & $\begin{array}{l}\text {...e agora mais poder contra os } \\
\text { mosquitos. }\end{array}$ \\
\hline 9 & $\begin{array}{l}\text { Aparece a logomarca Baygon sobre fundo verde com a frase: "O PODER É SEU". } \\
\text { No canto inferior direito, a beira da cena é ligeiramente levantada e aparece a } \\
\text { logomarca do fabricante sobre fundo azul. }\end{array}$ & $\begin{array}{l}\text { Baygon. } \\
\text { Voz em off canta - o poder é seu! }\end{array}$ \\
\hline
\end{tabular}

A peça publicitária do inseticida da marca Baygon também apela para a utilização de imagens de crianças. Ao contrário do inseticida SBP, que apresenta sempre um ambiente asséptico, o Baygon adota a estratégia de apresentar imagens do inseto real.

Apresenta uma dona de casa que tenta matar uma barata com a vassoura, mas esse procedimento faz com que o inseto se multiplique. Essa imagem nega que a contenção mecânica tenha algum poder de resolver o problema e, ao contrário, apela para a imagem surreal de que, através deste procedimento, as baratas se multiplicariam.

0 comercial induz à ideia de que só o inseticida tem o poder de matar baratas. Afirmações discutíveis acerca de uma solução instantânea, "sua nova fórmula age em segundos", e completa, "ação total", também são utilizadas para a persuasão do consumidor. 
Ao final, reafirma-se a autonomia do usuário em relação ao produto com a frase: "O poder é seu", dando ao usuário a sensação de domínio e controle da situação.

Recorre-se também ao sentido socialmente valorizado de cientificidade, pelo uso de ícones que associam o produto à excelência técnica através de comprovações por "testes laboratoriais". Com isso, atribui a este produto uma superioridade sobre os demais, o que não procede, uma vez que todo produto liberado para o mercado é avaliado por testes toxicológicos.

\section{Peça publicitária - Mortein:}

\section{Quadro 4 - Roteiro descritivo simples: Análise da peça publicitária - Mortein Rodox}

\begin{tabular}{|c|c|c|}
\hline \multicolumn{3}{|c|}{ Mortein - TV/TV Tem/Sessão da Tarde - Bauru/SP - 30" - 23/10/2009 } \\
\hline CENAS & VÍDEO & ÁUDIO \\
\hline 1 & $\begin{array}{l}\text { Dois insetos, uma mosca e uma barata, sobem sorrateiramente numa } \\
\text { mesa de cozinha. }\end{array}$ & Mosca-Vem, vem! Hehehe! \\
\hline 2 & $\begin{array}{l}\text { Enquanto a barata passeia em um açucareiro, a mosca vibra com a } \\
\text { diversão. }\end{array}$ & Vamos lá, que a farra tá boa! \\
\hline 3 & $\begin{array}{l}\text { Repentinamente, aparece uma mão humana segurando uma } \\
\text { embalagem do inseticida, que se aproxima ameaçadoramente do } \\
\text { "telespectador" e borrifa o produto sobre todos. }\end{array}$ & Voz masculina - Chegou Mortein Power Guard. \\
\hline 4 & $\begin{array}{l}\text { A barata e a mosca aparecem sob um foco de luz vermelha. Na } \\
\text { sequência, a mosca, muito zangada, esbofeteia e grita com a barata. }\end{array}$ & $\begin{array}{l}\text { Mosca - Barata burra! Aqui tinha Mortein Power } \\
\text { Guard! }\end{array}$ \\
\hline 5 & $\begin{array}{l}\text { Os insetos, no chão da cozinha e ainda sob o foco de luz vermelha, } \\
\text { veem apavorados uma imensa seta vermelha cair sobre eles. }\end{array}$ & $\begin{array}{l}\text { Voz masculina - Só o novo Mortein tem Power } \\
\text { Guard... }\end{array}$ \\
\hline 6 & A barata é atingida e, na agonia da morte, vira de barriga para cima. & ...uma fórmula com poder imbativel... \\
\hline 7 & $\begin{array}{l}\text { A barata aparece transparente para exemplificar a ação do inseticida } \\
\text { em seu organismo. Abaixo, a frase: "Mata na hora". }\end{array}$ & $\begin{array}{l}\text {...que mata na hora e continua matando por até } \\
6 \text { semanas. }\end{array}$ \\
\hline 8 & A linha de produtos Mortein é exibida por trás da mosca em pânico. & $\begin{array}{l}\text { Novo Mortein Power Guard. Poder imbativel do } \\
\text { primeiro ao último minuto. }\end{array}$ \\
\hline 9 & $\begin{array}{l}\text { Outra seta vermelha atinge a mosca. } 0 \text { endereço do site do produto } \\
\text { aparece junto com a frase: "Mantenha longe do alcance de crianças". } \\
\text { No alto, algo semelhante a um carimbo aparece com a frase: "A } \\
\text { FORÇA QUE PROTEGE". }\end{array}$ & $\begin{array}{l}\text { Mortein, a força que protege. Mantenha fora do } \\
\text { alcance de crianças. }\end{array}$ \\
\hline
\end{tabular}

Nesta peça, a técnica de persuasão está na ideia de força e poder, ao se afirmar que o produto é muito forte e eficaz. Utiliza desenhos de animação, (incluindo um conhecido personagem de desenho animado) que fazem parte do universo infantil, que a criança aprende a reconhecer e a identificar desde pequena. 0 comercial é barulhento, escuro e perturbador. Mostra cenas de violência em que a personagem mosca bate na barata e a insulta: "Barata burra! Aqui tinha Mortein Power Guard”.
Segundo a crítica publicada pelo Instituto Ala$n^{2}$, que inclusive conseguiu coibir a veiculação desta peça publicitária por longo período, a peça apresenta valores distorcidos, traz exemplos de conduta violenta e uso de linguagem inapropriada. Utiliza imagens de desenhos infantis, elementos que chamam a atenção da criança, e, ao mesmo tempo, a frase de advertência: "Mantenha fora do alcance das crianças”. Configura-se uma grande contradição na medida em que não se recomenda o manuseio de

3 INSTITUTO ALANA. Organização Não Governamental. Disponível em: <http://www.alana.org.br>. Acesso em: 14 set. 2010. 
inseticidas por crianças, uma vez que elas são mais suscetíveis à ocorrência de acidentes envolvendo tais produtos.

Nesta peça, a estratégia é mais agressiva, apelando para a ideia de força e potência absolutas: "Que mata na hora e continua matando por até 6 semanas".

\section{Estratégias de persuasão identificadas nas peças publicitárias}

O presente estudo dos conteúdos das peças publicitárias teve como foco identificar estratégias adotadas pelas indústrias para comercialização e venda de inseticidas. Sem a pretensão de esgotar o tema ou de se apropriar de categorias de análise de discurso publicitário, estabelecemos cinco categorias empíricas principais, que são passíveis de novas interpretações e ressignificações. Tais categorias representam um primeiro esforço de análise empírica dos conteúdos que a mídia veicula regularmente, estimulando o exacerbado consumo de inseticidas. São escassos os estudos sobre a percepção, por parte de setores da sociedade, das estratégias de persuasão e de ocultação de riscos destes produtos. As categorias aqui apresentadas estão também sendo utilizadas como parâmetros em um estudo em andamento acerca da interpretação pública das peças publicitárias em grupos de consumidores de diferentes classes sociais.

1. Apelo ao status do usuário - Nesta categoria foram incluídas as estratégias adotadas para evocar o desejo de identificação do(a) consumidor(a) com modelos de comportamento e status socialmente valorizados. Aparecem famílias unidas, relacionamentos harmoniosos e apelo à identificação com a imagem da mulher moderna e bem-sucedida, como um exemplo a ser seguido. Outras peças publicitárias, que não as analisadas aqui, lançam mão, neste sentido, da imagem de artistas famosos consumindo o produto.

2. Ocultação e minimização dos riscos - Imagens de crianças brincando, brinquedos, alimentos, flores e afirmações de que o produto não preju- dica o meio ambiente, entre outros, reforçam a ideia de inocuidade dos inseticidas anunciados. Afirmações de que o produto atua somente contra os insetos, de que é feito utilizando a água como solvente, de que não tem cheiro e outras estratégias, como o uso de aromatizantes, são utilizadas para induzir o consumidor a pensar que o produto é inofensivo. Também ocorre a omissão de advertência acerca do potencial tóxico do produto (ausente nas peças publicitárias e presente na rotulagem). Apenas duas das peças analisadas informaram que esses produtos devem estar fora do alcance das crianças.

3. Símbolos de modernidade e cientificidade Apelo à identificação com avanços tecnológicos: spray e dispositivos de liberação automática do produto. Negação de práticas de controle mecânico de insetos, apresentando o uso da vassoura como obsoleto (imagem da dona de casa tendo o problema aumentado ao tentar matar baratas) e o ato de espantar insetos sendo representado como uma ação primitiva (realizado pelo macaco no zoológico). Utiliza a informação de que o produto é "avaliado por toxicologistas" e "comprovado por testes laboratoriais" atribuindo superioridade e confiabilidade ao produto. Muitas peças publicitárias apelam para imagens de cientistas e para o uso de gráficos e tabelas como ícones de cientificidade.

4. Representações de um mundo asséptico - Utilização de imagens de ambientes claros, iluminados e limpos, representando a higiene e assepsia. Ausência de imagens de insetos, que são o objeto da finalidade do produto. Utilização da imagem da casa envolta numa bolha, representando proteção e impermeabilidade ao mundo externo.

5. Representações de força, poder e controle -Apelo à agressividade e competição. Utiliza frases que promovem no usuário a sensação de domínio sobre a situação, de potência, "O poder é seu”, e de controle sobre o problema, "que mata na horae continua matando por até 6 semanas”. Apresenta imagens de insetos que são exterminados pela ação do inseticida. 


\section{Discussão}

Venenos, por conceito, são substâncias capazes de provocar a morte de espécies vivas, mesmo quando utilizados em pequenas quantidades. Este conceito clássico foi esmaecendo no trato cotidiano das ações de controle de pragas e foi substituído pela palavra "remédio", numa verdadeira perda do significado original (Castro, 1999; Peres et al., 2001; Augusto et al., 200o). É comum a naturalização e a banalização dos riscos decorrentes destas substâncias, o que reflete interesses estratégicos de mercado.

Da mesma forma, nos programas de controle dos vetores, difundiu-se o emprego de termos como "tratamento" ou "tratamento focal" para o uso de biocidas, induzindo a comparação com termos empregados na medicina clínica, na utilização de fármacos para o ato de curar.

Essa analogia, historicamente construída pela Saúde Pública, entre o uso de substâncias tóxicas e o uso de fármacos, promove a ocultação de risco. Nesse sentido, o senso comum relacionado com o uso de biocidas naturalizou expressões como "remédio para barata", "remédio para mosquito", "remédio para ratos" no lugar de "veneno para barata", "veneno para mosquito" e "veneno para ratos". Essa cultura, obviamente, favorece a indústria e o mercado de inseticidas e encobre os riscos para a saúde dela decorrentes (Santos; Augusto, 2005; Augusto, 2003).

Uma postura pragmática, por parte da política de controle dos vetores, permeia a produção do aparente conforto advindo da extensiva utilização de agentes químicos tóxicos na agricultura, nos lares e na saúde pública, afastando-se da cautela que a aplicação do Princípio de Precaução recomenda adotar (Teixeira, 2000; Londres, 2011).

Além disso, o uso de inseticidas domésticos nos lares é uma prática, carregada de sentido de "modernidade", muito difundida, que parece se contrapor às antigas práticas de proteção à saúde, como o uso de mosquiteiro e de tela nas portas e janelas, que foram gradualmente abandonados pela população como obsoletos.

Todas as propagandas aqui analisadas utilizaram estratégias que ocultam o risco dos inseticidas no ambiente doméstico e não cumprem a legislação sobre domissanitários, em relação ao Artigo 59 da Lei nº 6.36o, de 23/o9/1976. Ferem os preceitos básicos do CONAR (Conselho Nacional de Autorregulação Publicitária) que definem a ética publicitária:"todo anúncio deve ser honesto e verdadeiro e respeitar as leis do país" e "deve ser preparado com o devido senso de responsabilidade social" (Brasil, 1976; Conar, 2012).

Ainda, no que tange especificamente à propaganda e rotulagem, o Artigo 59 define que:

Art. 59 - Não poderão constar de rotulagem ou de propaganda dos produtos de que trata esta Lei designações, nomes geográficos, símbolos, figuras, desenhos ou quaisquer indicações que possibilitem interpretação falsa, erro ou confusão quanto à origem, procedência, natureza, composição ou qualidade, que atribuam ao produto finalidades ou características diferentes daquelas que realmente possuam (Brasil, 1976).

Outra questão importante é o embate ético e mercadológico que a propaganda enfrenta ao usar crianças como apelo persuasivo. Ao envolvê-las com produtos que devem estar fora de seu alcance, tais como os inseticidas, entendemos que a propaganda está ultrapassando o limite e contrariando a legislação em vigor (Rodrigues, 2006).

Esta prática, a de endereçar a comunicação mercadológica à criança, tem sido conduta cada vez mais comum, ainda que o produto anunciado não seja primordialmente direcionado para uso infantil (Conar, 2012). Segundo dados da InterScience (Informação e Tecnologia Aplicada), atualmente as crianças influenciam em até $80 \%$ das compras da casa $(38 \%$ influenciam fortemente e $42 \%$ influenciam um pouco). As agências publicitárias sabem de antemão que dirigindo maciçamente suas publicidades, mesmo de produtos de uso adulto, para o público infantil, terão forte impacto sobre as decisões de consumo da família, na medida em que as crianças passam a, literalmente, promover o produto anunciado (Instituto Alana).

Além disso, segundo Martins, Andrade e Paiva (2006), os envenenamentos (ou intoxicações) representam um dos principais tipos de acidente envolvendo crianças, e alcançam uma dimensão preocupante. Na sua grande maioria, são consi- 
derados acidentais, porém decorrem de situações facilitadoras, de características peculiares às fases da criança, de comportamentos inadequados da família e do pouco incentivo às medidas preventivas. 0 autor ressalta ainda que os acidentes domésticos entre crianças são frequentes e contribuem para elevar a morbimortalidade infantil.

\section{Conclusão}

Concluímos que todas as propagandas analisadas utilizaram estratégias que ocultam o risco dos inseticidas no ambiente doméstico e não cumprem a legislação.

As peças publicitárias dos inseticidas aqui analisadas utilizam mensagens de que esses produtos são inócuos, que protegem a saúde e o ambiente, ocultando seus riscos, levando à utilização indiscriminada, à contaminação do meio e, consequentemente, ao aumento da resistência dos insetos ao uso do produto, o que faz com que o consumidor venha a usar mais o inseticida, ampliando o risco de intoxicações.

Os programas de informação e comunicação que atualizem o consumidor certamente não serão de iniciativa da indústria e suas agências de marketing e publicidade, e sim do Estado, por meio dos órgãos públicos de saúde e ambiente. Neste sentido, promover ações informativas e educativas para a construção de uma consciência sanitária agrega valores à cidadania e mostra responsabilidade com relação à saúde humana e ambiental, o que faz parte das ações do Estado.

Para Nascimento (2007, p. 276), "as exigências do consumo e das práticas de marketing submetem a população a risco permanente, fazendo sobrepor os interesses do setor regulado aos da sociedade e da saúde pública".

Neste contexto, o maior desafio é fazer com que a ANVISA cumpra o seu papel de vigilância, fiscalização e monitoramento das propagandas de inseticidas que ferem claramente o disposto na legislação.

\section{Referências}

\footnotetext{
ABIPLA - ASSOCIAÇÃO BRASILEIRA DAS INDÚSTRIAS DE PRODUTOS DE LIMPEZA E AFINS. Anuário Abipla 2011. 6. ed. São Paulo: Public Projetos Editoriais, 2011. Disponível em: <http://www.abipla.org.br/novo/anuario.aspx>. Acesso em: 25 fev. 2013.
}

ANVISA - AGÊNCIA NACIONAL DE VIGILÂNCIA SANITÁRIA. Programa de Análise de Resíduos de Agrotóxicos em Alimentos (PARA): relatório anual 04/o6/2001-30/o6/2002. Brasília, DF, 2003. Disponível em: <http://s.anvisa.gov.br/wps/s/r/z>. Acesso em: 14 ago. 2008.

AUGUSTO, L. G. S. Saúde e vigilância ambiental: um tema em construção. Epidemiologia e Serviços de Saúde, Brasília, DF, v. 12, n. 4, p. 177-187, 2003.

AUGUSTO, L. G. S.; CARNEIRO, R. M.; MARTINS, P. H. Abordagem ecossistêmica em saúde: ensaios para o controle do dengue. Recife: Universitária UFPE, 2005 .

AUGUSTO, L. G. S. et al. Avaliação crítica do programa de erradicação do Aedes aegypti: contribuições técnicas para medidas de controle. Revista IMIP, Recife, v. 14, n. 1, p. 90-97, 2000.

BRAGA, I. A.; VALLE, D. Aedes aegypti: inseticidas, mecanismos de ação e resistência. Epidemiologia e Serviços de Saúde, Brasília, DF, v. 16, n. 4, p. 279293, 2007.

BRASIL. Lei n 6.36o, de 23 de setembro de 1976. Dispõe sobre a vigilância sanitária a que ficam sujeitos os medicamentos, as drogas, os insumos farmacêuticos e correlatos, cosméticos, saneantes e outros produtos, e dá outras providências.

Diário Oficial da União, Brasília, DF, 24 set. 1976. Disponível em: <http://www.planalto.gov.br/ ccivil_o3/Leis/L636o.htm>. Acesso em: 26 nov. 2010.

BRASIL. Lei n ${ }^{0} 7.802$, de 11 de julho de 1989. Dispõe sobre a pesquisa, a experimentação, a produção, a embalagem e rotulagem, o transporte, o armazenamento, a comercialização, a propaganda comercial, a utilização, a importação, a exportação, o destino final dos resíduos e embalagens, o registro, a classificação, o controle, a inspeção e a fiscalização de agrotóxicos, seus componentes e afins, e dá outras providências. Diário Oficial da União, Brasília, DF, 12 jul. 1989. Disponível em: <www.planalto.gov.br/ccivil_03/ Leis/L7802.htm>. Acesso em: 21 out. 2010. 
BRASIL. Agência Nacional de Vigilância Sanitária (Anvisa). Reavaliação de agrotóxicos: 10 anos de proteção a população. Brasília, DF, 2009. Disponível em: <http://www.anvisa.gov.br/divulga/ noticias/2009/020409.htm>. Acesso em: 2 abr. 2009.

CÂMARA, H. F. Condições sanitárias do ambiente urbano e o uso de pesticidas domésticos: implicações para a saúde. 20oo. Dissertação (Mestrado em Saúde Pública) - Centro de Pesquisa Argeu Magalhães, Recife, 2000.

CASTRO, J. S. M. Práticas de uso de agrotóxicos no município de Cachoeiras de Macacu, RJ: um estudo de saúde ambiental. 1999. Dissertação (Mestrado em Ciência Ambiental) - Universidade Federal Fluminense, Niterói, 1999.

COLBORN, T.; DUMNOSKI, D.; MYERS, J. P. $O$ futuro roubado. Porto Alegre: L\&PM, 2002.

CONAR - CONSELHO NACIONAL DE AUTORREGULAÇÃO PUBLICITÁRIA. Cidadãos responsáveis e consumidores conscientes dependem de informação (e não da falta dela). São Paulo, 2012. Disponível em: <www.conar.org.br/ conar-criancas-e-adolecentes.pdf>. Acesso em: 15 jan. 2015.

CRIVELARO, L. P. et al. A publicidade na TV e sua influência na obesidade infantil. UNIrevista, São Paulo, v. 1, n. 3, p. 1-7, 2006.

DAL COL, A. A.; BRASIL, L. F. Técnicas argumentativas nas propagandas comerciais. Estudos Linguísticos, São Paulo, v. 38, n. 3, p. 469480, 2009 .

DIEL, C.; FACCHINE, L. A.; DALL'AGNOL, M. M. Inseticidas domésticos: padrão de uso segundo a renda per capita. Revista de Saúde Pública, São Paulo, v. 37, n. 1, p. 83-90, 2003.

DONALÍSIO, M. R.; GLASSER, C. M. Vigilância entomológica e controle de vetores do dengue. Revista Brasileira de Epidemiologia, São Paulo, v. 5, n. 3, p. 259-272, 2002.

FARIA, N. M. X.; FASSA, A. G.; FACCHINI, L. A. Intoxicação por agrotóxico no Brasil: os sistemas oficiais de informação e desafios para a realização de estudos epidemiológicos. Ciência \& Saúde Coletiva, Rio de Janeiro, v. 12, n. 1, p. 25-38, 2007.
GURGEL, I. G. D. Saúde dos trabalhadores que atuam no controle de endemias vetoriais. In: AUGUSTO, L. G. S.; CARNEIRO, R. M.; MARTINS, P. H. (Org.). Abordagem ecossistêmica em saúde: ensaios para o controle do dengue. Recife: Universitária UFPE, 2005. p. 227-234.

LARINI, L. Toxicologia. 2. ed. São Paulo: Manole, 1993.

LOMBARDI, M.; MINUISSI, J.; MIDIO, A. Aspectos toxicológicos de inseticidas de uso doméstico. Revista Brasileira de Saúde Ocupacional, São Paulo, v. 11, n. 41, p. 36-48, 1983.

LONDRES, F. Agrotóxicos no Brasil: um guia para ação em defesa da vida. Rio de Janeiro: AS-PTA Assessoria e Serviços a Projetos em Agricultura Alternativa, 2011.

LOPES, M. E. B. M.; ALMEIDA JÚNIOR, A. R. Agrotóxicos: uma análise das matérias jornalísticas em cinco veículos de comunicação. In: CONGRESSO BRASILEIRO DE CIÊNCIAS DA COMUNICAÇÃO, 31. 2008, Natal. Anais... São Paulo: Intercom, 2008. [s/p]. Disponível em: <www.intercom.org.br/papers/nacionais/20o8/ resumos/R3-1348-1.pdf>. Acesso em: 22 fev. 2015.

MARTINS, C. B. G.; ANDRADE, S. M.; PAIVA, P. A. B. Envenenamentos acidentais entre menores de 15 anos em município da Região Sul do Brasil. Cadernos de Saúde Pública, Rio de Janeiro, v. 22, n. 2, p. 407-414, 2006.

MEYER, A. et al. Os agrotóxicos e sua ação como desreguladores endócrinos. In: PERES, F.; MOREIRA, J. C. (Org.). É veneno ou é remédio: agrotóxicos, saúde e ambiente. Rio de Janeiro: Fiocruz, 2003. p. 101-118.

MINAYO, M. C. de S. O desafio do conhecimento: pesquisa qualitativa em saúde. 8. ed. São Paulo: Hucitec; Rio de Janeiro: Abrasco, 2004.

MOREIRA, J. C. et al. Avaliação integrada do impacto do uso de agrotóxico sobre a saúde humana em uma comunidade agrícola de Nova Friburgo, RJ. Ciência \& Saúde Coletiva, Rio de Janeiro, v. 7, n. 2, p. 299-311, 2002.

NASCIMENTO, A. C. Ao persistirem os sintomas o médico deverá ser consultado: isto é regulação? São Paulo: Sobravime, 2005. 
NASCIMENTO, A. C. Propaganda de

medicamentos: é possível regular? 2007. Tese (Doutorado em Saúde Coletiva) - Universidade do Estado do Rio de Janeiro, Rio de Janeiro, 2007.

NEVES, K. Mercado de inseticidas cresce na guerra contra as pragas urbanas. $H \& C$ - Household \& Cosméticos, v. XIII, n. 73, 2012. Disponível em: $<$ http://www.freedom.inf.br/revista/hc73/saz household.asp>. Acesso em: 25 fev. 2013.

OLIVEIRA, E. E. et al. Resistência vs susceptibilidade a piretróides em Sitophilus zeamais Motschulsky (Coleoptera: Curculionidae): há vencedor? Neotropical Entomology, Londrina, v. 34, n. 6, p. 981-990, 2005.

PAIVA, K. B. S.; MENEZES, M. L. Avaliação do emprego dos adsorventes: carvão ativo, chomosorb w e membrana C18 na preparação de amostras de ar para a determinação de D-aletrina em ambientes fechados. Eclética Química, São Paulo, v. 28, n. 1, p. 97-103, 2003.

PERES, F. et al. Comunicação relacionada ao uso de agrotóxicos em região agrícola do Estado do Rio de Janeiro. Revista de Saúde Pública, São Paulo, v. 35, n. 6, p. 564-570, 2001.

PINTO, M. A. O. Aspectos legais e análise de conteúdo de propagandas impressas de alimentos com alegações de propriedades funcionais. 2008. Tese (Doutorado em Ciência e Tecnologia de Alimentos) - Universidade Federal de Viçosa, Viçosa, 2008.

PRESGRAVE, R. F.; CAMACHO, L. A. B.; VILLAS BOAS, M. H. S. Análise dos dados dos Centros de Controle de Intoxicação do Rio de Janeiro, Brasil, como subsídio às ações de saúde pública. Cadernos de Saúde Pública, Rio de Janeiro, v. 25, n. 2, p. 401-408, 2009.
RABELLO, E. T.; CAMARGO JÚNIOR, K. R. Drug advertising: health as a consumer product. Interface - Comunicação, Saúde, Educação, São Paulo, v. 16, n. 41, p. 357-367, 2012.

RESENER, M. C.; SCHENKEL, E. P.; SIMÕES, C. M. O. Análise da qualidade de propagandas de medicamentos fitoterápicos disponibilizadas em Santa Catarina (Brasil). Acta Farmcéutica Bonaerense, Buenos Aires, v. 25, n. 4, p. 583-589, 2006.

RODRIGUES, C. D. R. Perto do alcance das crianças. In: CONGRESSO BRASILEIRO DE CIÊNCIAS DA COMUNICAÇÃO, 39. 2006, Brasília, DF. Anais... São Paulo: Intercom, 2006. s/p.

SANTOS, S. L.; AUGUSTO, L. G. S. Modelo de controle de dengue, pontos e contrapontos. In: AUGUSTO, L. G. S.; CARNEIRO, R. M.; MARTINS, P. H. (Org.). Abordagem ecossistêmica em saúde: ensaios para o controle do dengue. Recife: Universitária UFPE, 2005. p. 115-133.

SOARES, J. C. R. S. Quando o anúncio é bom, todo mundo compra: o projeto Monitoração da Propaganda de Medicamentos no Brasil. Ciência \& Saúde Coletiva, Rio de Janeiro, v. 13, p. 641-649, 2008. Suplemento 1.

TEIXEIRA, C. F. Exposição ocupacional aos inseticidas e seus efeitos na audição: a situação dos agentes de saúde pública que atuam em programas de controle de endemias vetoriais em Pernambuco. 200o. Dissertação (Mestrado em Saúde Pública) - Centro de Pesquisa Argeu Magalhães, Recife, 2000.

\section{Contribuição dos autores}

As autoras participaram igualmente na concepção e no delineamento da pesquisa, análise e interpretação dos dados.

Recebido: 16/09/2013

Reapresentado: 13/03/2014

Aprovado: 28/03/2014 